\title{
¿Vocación temporal?
}

El P. A. Turrado, O. S. A., ha publicado un artículo en Estudio Agustiniano 1 sobre "T'eología de la vocación religiosa". Su segunda parte la dedica al espinoso problema de la posible vocación temporal. Por su importancia, no sólo teórica, sino sobre todo práctica, merece la pena dedicarnos a pensar un poco el problema. T'odo to que se aporte en un tema tan delicado es digno de encomio.

T'engo que reconocer y alabar el tono mesurado con que el $P$. Turrado trata una cuestión tan delicada, con resonancias indiscutiblemente profundas en las almas religiosas. El P. Turrado no defiende, sin más ni más, la temporalidad de la vocación. Habla de una posible vocación temporal. En esta misma línea quiero situarme yo. Quiero adoptar un tono de diálogo, mesurado, sin dogmatismos. Pero, al mismo tiempo, real y objetivo. Pienso que es la única forma de lograr un camino viable en la difícil búsqueda de la verdad. Que no por difícil es lícito abandonar o desconocer.

Esto supuesto, entro ya de lleno en el tema de la vocación religiosa. El artículo constará de dos partes. Una, de crítica. Trataré de demostrar la falta de solidez en la argumenación del P. Turrado. Otra, positiva, en la que expondré las razones que avalan una vocación para toda la vida.

\section{FALTA DE SOLIDEZ EN LOS ARGUMENTOS A FAVOR DE UNA POSIBLE VOCACION TEMPORAL}

El P. Turrado inicia su segunda parte del artículo, en la que propiamente plantea el tema de la vocación, con algunas observaciones previas. Recojo las que interesan a mi propósito. Estoy plenamente conforme con lo que el P. Turrado dice acerca del excesivo juridismo con que se ha enfocado frecuentemente el problema de la vocación. Lo mismo, sobre el personalismo, que deriva fundamentalmente de la doctrina de San Agustín. Y que contrapone al esencialismo, que atribuye a la desprestigiada filosofía Aristotélico-Tomista. Todo esto es ciento,

1 Estudio Agustiniano 3 (1968) 505-526. 
evitando, como es lógico, exageraciones pueriles. $Y$, ya que se concede tanta autoridad a San Agustín, hubiera estado muy acertado recoger su doctrina acerca de la fidelidad al "sanctum propositum" 2 . Y esto sin atribuir ni en esto ni en otras cosas carta de infabilidad al gran Doctor.

Acepto también las situaciones-límites, en que puede encontrarse el religioso y que, no sólo acogen, sino impongan un abandono de la vida religiosa. Y ciertamente no hay que asustarse ni hacer cruces diciendo: ¡Caen los cedros del Líbano! La conciencia es un santuario tan sagrado que a ningún hombre le es lícito violar. Nosotros debemos adorar en silencio, desde fuera, lo que sólo puede ser comprendido desde dentro.

Ya ve, P. Turrado, hay muchas cosas en las que estamos de acuerdo. Pero aquí comenzamos a distanciarnos. $Y$ esta distancia comienza a realizarse en el momento en que se inicia la crítica de las razones en defensa de una posible vocación temporal.

Inicia el P. Turrado su argumentación recordando dos clásicos principios del Tratado de "Gratia". Son ellos: "La gracia presupone a la naturaleza". "La gracia no destruye, sino que perfecciona la naturaleza". Inmediatamente afirma, con toda verdad, que esa naturaleza, presupuesta por la gracia y por ella perfeccionada, es la naturaleza concreta, existencial. No se trata, como se pudiera deducir de la filosofía Aristotélico-Tomista, de una naturaleza esencializada o despersonalizada. Y concluye: "Todo esto nos lleva a la conclusión de que esa naturaleza, presupuesta por la gracia y, por lo tanto, presupuesta también por la vocación religiosa, es la naturaleza concreta de cada persona, tan misteriosa como la vida del hombre, sujeta a un sin fin de evoluciones ppsico-fisiológicas que muy fácilmente pueden llegar a ser incompatibles con las decisiones perentorias, en nuestro caso con los votos solemnes y perpetuos, tomadas en un momento dado de la existencia. De este modo se comprende mejor que la temporalidad, aunque con diversos matices, sea un elemento esencial del dinamismo de la naturaleza humana $y$, por lo mismo, esencial también al dinamismo de la gracia" 3 .

¿Qué decir a todo esto? El P. Turrado no parece apreciar la desproparción que existe entre la primera parte y la segunda de su conclusión. Acepto que la naturaleza, presulpuesta por la gracia y, por tanto, por la vocación religiosa, es la

2 "Mas, como ya te has prometido, ya te has atado y no te es lícito hacer otra cosa. Antes de ser reo de voto, eras libre para elegir un estado inferior; aunque no había de felicitarte por una libertad que permite no pagar lo que se devuelve con ganancia. Mas ahora que tu voto fue aceptado por Dios, no te invito a una gran justicia, sino que te quiero apartar de una gran iniquidad. Porque, si no cumples lo que prometiste, no quedarás en el mismo estado que tuvieras, si nada hubieses prometido. Entonces hubiese sido no peor, sino menor tu estado. En cambio, si ahora quebrantases la fe que debes a Dios (El te libre de cllo), serás tanto más miserable, cuanto serás más feliz si se la mantienes". (Epist. 127, 8.)

3 Art. cit. 523. 
naturaleza concreta de cada persona. ¿Qué puede concluir de aquí el P. Turrado? ¿La incompatibilidad con los compromisos perentorios? ¿Que la temporalidad es un elemento esencial del dinamismo de la naturaleza humana? Eso parece. Mas estas conclusiones desbordan el contenido que encierra la naturaleza concreta $y$, si se quiere, el personalismo agustiniano. Dicho en otros términos: la segunda parte no se puede deducir, en buena lógica, de la primera, so pena de interpretar equivocadamente el concepto de naturaleza. Y, si no ¿cómo se puede entender el compromiso perenne del vínculo matrimonial? $\mathrm{Y}$ ¿de la vocación cristiana? $Y$ ¿die la vocación sacerdotal? A no ser que el P. Turrado también niegue esto. Y debiera hacerlo, si fuera lógico. En consecuencia: lo que prueba demasiado, no prueba nada.

Además ahondemos un tanto en la raíz filosófica del problema. Esta naturaleza concreta, a la que se refiere el P. Turrado, misteriosa y sometida a un sin fin de evoluciones psico-fisiológicas, no es tan vulnerable a dichas evoluciones que desaparezca totalmente. Hay algo que permanece como elemento de cohesión y que hace posible la existencia de esas variaciones. Elemento de cohesión que se constituye en base, no sólo de las variaciones, sino también de aquellas cosas que afectan de manera permanente al hombre 4 . "No es necesario explicar largamente que esta constitución ontológica (no solamente lógica) del hombre es el fundamento de su validez eterna, de su responsabilidad, de su relación dialógica con Dios, de su capacidad a ser llamado a un fin sobrenatural, de su dignidad e inmortalidad, del carácter absoluto de los valores morales" ${ }^{5}$.

A estas razones, de carácter eminentemente filosófico, podemos añadir otra que se mueva en un campo más bien psicológico. Recordemos, y creo que el P. Turrado esté de acuerdo en ello, que la iniciativa de la vocación religiosa parte de Dios. Esta llamada, por lo demás, se dirige al individuo, es decir, a la persona en concreto. Por tanto, con su fisonomía personal, como es la realidad concreta que circunda al individuo. Ahora bien, si Dios hace las cosas con un poco de

4 Y no se tache ésto de resabio aristotélico-tomista. Esto es de sentido común, pues sólo así se puede encontrar el punto de apoyo para poder llegar hasta la verdad. Y la verdad ni es platónica, ni aristotélica, ni agustiniana, ni tomista... Es humana. Por si esto fuera poco, recojo unas palabras del Papa dichas en ocasión solemne ante el episcopado latino-americano: "Y sabemos también cómo la fe es insidiada por las corrientes más subversivas del pensamiento moderno. La desconfianza, que, inclusive en los ambientes católicos se ha difundido acerca de la validez de los principios fundamentales de la razón, o sea, de nuestra philosophia perennis, nos ha desarmado frente a los asaltos, no raramente radicales y capciosos, de pensadores de moda... Estamos tentados de historicismo, de relativismo, de subjetivismo, de neopositivismo, que en el campo de la fe crean un espíritu de crítica subversiva y una falsa persuasión de que para atraer y evangelizar a los hombres de nuestro tiempo tenemos que renunciar al patrimonio doctrinal, acumulado durante siglos por el magisterio de la Iglesia". (Discurso al Episcopado latino-americano. "El Heraldo de la Reina", número 55. Bogotá, sept. 68.)

5 Rahner y Vorgrimler, Diccionario Teqlógico, Herder, Barcelona 1966). 
seriedad, y ello es un presupuesto justo, hay que concluir necesariamente que de ley ordinaria Dios llama para toda la vida. Lo demás sería crear una situación psicológica angustiosa e insostenible. Afirmar lo contrario es pensar que Dios está jugando con el hombre al escondite. $Y$ esto creo que ni es justo afirmarlo ni es lícito suponerlo.

$Y$ no se acuda a los cambios psicofisiológicos insertos en el dinamismo de la persona humana. De ellos se hablará más adelante para colocarles en su justo punto.

Por lo demás la seriedad de la vida parece pedir un tanto die estabilididad en la vocación que cada uno escoge. Esto hay que afirmarlo con muchísimo más énfasis al referirse a la vida religiosa. Su situación concreta dentro del marco de la vida humana está exigiendo perennidad. Usted mismo, P. Turrado, la reconoce, cuando escribe: "Todos los carismas, tanto la gracia habitual y las gracias actuales como los carismas extraordinarios, ordenados a la perfección propia y del prójimo, tienden de por sí a la perennidad, como es perenne la voluntad salvífica de Dios que los otorga" 6 .

Reconozco, como ya lo dije al principio, que se puedan dar situaciones-límites en que no sólo se aconseje sino que se imponga el abandono de la vida religiosa. Mas es ilícito deducir de situaciones extremas y, por tanto excepcionales, la existencia de una ley universal.

Una vez criticado el principio, paso a estudiar una por una las causas que, como consecuencia de dicho principio, llevan al $\mathrm{P}$. Turrado a pensar en la posible temporalidad de la vocación.

La primera, y no de escasa importancia, es la posible ignorancia de la materia de los votos. La acepto como posible y también como real. Pero de ello no se puede deducir la temporalidad de la vocación. Esta, como tal, es anterior al conocimiento de la materia de los votos y queda siempre al margen de la posible ignorancia de la misma. No quiero afirmar con ello que haya que mantener la vocación por encima y a pesar de la ignorancia de los compromisos adquiridos. Sencillamente digo que son dos cosas distintas y que la vocación subsiste, aunque no resulte viable a consecuencia de la ignorancia.

Por otra parte, la Iglesia ha dado normas muy claras y precisas para evitar tales despropósitos. Los formadores tienen conciencia de ello y deben esforzarse por llevarlo a la práctica. Y no se moteje a este conocimiento de especulativo. Creo que en las presentes circunstancias es muy difícil calificarlo de tal. Los formandos tienen las suficientes experiencias como para pensar, si quieren ser sinceros, en una formación, sino totalmente perfecta, sí lo suficiente para pronunciar los votos con garantía. El mal nace, no tanto de la posible ignorancia, cuanto del

6 Art. cit. 523. 
abandono de aquellos medios indispensables para la práctica de los votos religiosos.

Alude el P. Turrado en defensa de esta primera causa la praxis de la Sagrada Congregación de Religiosos, ya que concede con relativa facilidad la dispensa de los compromisos adquiridos. Sin embargo, profundamente preocuipada, la Sagrada Congregación ha dado normas que nos inducen a pensar más seriamente dicho problema. Lo cual sería inconcebible en una postura de posible vocación temporal ?.

La segunda de las causas, aducidas por el $\mathrm{P}$. Turrado, es la posible evoluoión Ipsico-fisiológiloa. Y, para más datos, imprevista.

Ya que se sitúa en un campo psicológico, desde él quiero hacer la crítica. ¿Qué nos dice la Psicología acerca de esas evoluciones psico-fisiológicas? Ciertamente la psicología moderna nos habla de esos procesos evolutivos. Procesos que pueden y deben tener un desarrollo normal y, por tanto, de ellos nadie se puede

7 1. Las peticioncs de dispensas de votos deberán ser dirigidas a Su Santidad. Una simple carta al Superior General pidiendo aue obtenga la dispensa no es suficiente. Se espera que al darse cuenta de que la dispensa ha de obtenerse del Vicario de Cristo, sirva también para impresionar al peticionario de la gravedad del paso que intenta dar.

2. El Superior General, con la ayuda del Provineial y del Superior local, deberá recoger todos los papeles necesarios y mirar de enviarlos cuanto antes a la Sagrada Congregación. Las peticiones enviadas directamente a la Sagrada Congregación por el interesado sólo causarán pérdida innecesaria de tiempo, puesto que no se tomará ninguna medida hasta después de haberlas devuelto al Superior General para que añada sus comentarios y posible aprobación.

3. Cada pctición deberá presentar con breve, pero concreto, detalle las razones actuales que motivan la petición. Si el peticionario lo desea, estas razones se pueden presentar en sobre sellado dirigido a la Sagrada Congregación de Religiosos, aue el competente Superior enviará con fidelidad a Roma junto con los atros documentos necesarios.

4. No se aceptan razones vagas, v. gr.: "No auiero permanecer más en la vida religiosa". "No soy feliz en la vida de comunidad". "Me doy cuenta que no puedo vivir baio ninguna limitación impuesta desde fuera". Estas expresiones son meras declaraciones de un hecho, y no la explicación de los motivos.

5. La petición deberá indicar del mismo modo qué medios -espirituales, psicológicos o médicos- se han usado para dar solución a los problemas existentes antes de haber recurrido a la solución extrema de dispensa de los votos.

6. Se deberá incluir un curriculum vitae, del peticionario, indicando las diferentes ocupaciones, etc. oue se han dado al religioso y una evaluación de su modo de proceder en actividades' apostólicas anterior, haciendo especial referencia al éxito o carencia de él en el campo de las relaciones comunitarias.

7. La petición deberá ser acompañada de una valoración objetiva de su ambiente general hecha por el Superior Provincial, lo mismo que de la aprobación razonada, no genérica, del Superior General. Ordinariamente, ninguna petición de dispensa será atendida por la Sagrada Congregación sin la aprobación explícita del Superior General.

Añade el articulista: La Sagrada Congregación espera que esta actitud de mayor rigor llevará a no pocos religiosos a pensar dos veces la gravedad de pedir una dispensa de votos perpetuos y puede ayudar a detener el desaliento en las primeras dificultades de la vida religiosa, poniendo en claro que los problemas se pueden solucionar con frfcuencia sin acudir al extremo de una dispensa de votos. (Tomado de Vida Religiosa 26 (1969) 113.) 
eludir pues forman parte substancial del dinamismo humano. Nadie tiene por qué extrañarse ante tales procesos evolutivos. Con ellos tiene que contar quien se decide a entrar en la vida religiosa.

La influencia en la conducta del hombre es indiscutible. El grado de la misma ya no lo es tanto. Más aún: Si se consideran normales, su influencia estará enmarcada dentro de un ámbito ordinario. Por eso afirma Cerdá: "Hasta época muy reciente era frecuente explicar gran parte del comportamiento humano recurriendo a los instintos... investigaciones realizadas durante las últimas décadas han restringido considerablemente el papel que se asignaba a los instintos como deter. minantes del comportamiento humano" ${ }^{8}$. En consecuencia la Psicología, que ha descubierto esos procesos evolutivos, valora y puntualiza su alcance. $\mathrm{Ni}$ se puede exagerar ni tampoco minimizar su influencia. No echemos culpas al que en realidad no las tiene. Si el hombre está sometido a procesos que, en definitiva, no dependen de su voluntad, también cuenta de ley ordinaria con elementos abundantes para superar su acción negativa. Recojo las palabras ponderadas del doctor Paul Chauchard: "Con réspecto a una vocación, nunca se tiene certeza absoluta : se precisa una ayuda para ver claro antes de comprometerse. Pero una vez que uno se ha comprometido sólo puede considerarse como adulto a quien sabe permanecer fiel (y hacer auténtico, si fuera preciso, un compromiso adoptado - a lo mejor- por motivos parcialmente erróneos); quien no sabe afirmarse es solamente un adolescente inmaduro.

Se piensa, demasiado a menudo, que el equilibrio humano es tarea de los medicamentos cerebrales o de la exploración psico-analítica del inconsciente (co. sas que son medios terapéuticos para enfermos). $\mathrm{Y}$ se olvida que el verdadero camino para el equilibrio, para el propio autocontrol; que la vía pedagógica para la humanización marcha al filo de una ascesis vivificante que -un cuenpo en armonía con el mundo - nos enseña a equilibrarnos por la buena sugestión de tener presente la verdad, la belleza, el bien y la alegría ${ }^{9}$.

El P. Turrado se refiere sin duda a casos excepcionales, a posibles taras hereditarias o ambientales, que colocan tales procesos evolutivos en situación anormal Pueden existir y de hecho existen. Para valorarlos en relación con la vocación hay que tener en cuenta que se trata de casos excepcionales, que no pueden, de suyo, afectar a la ley ordinaria. Más aún: en tales situaciones no se puede hablar ni siquiera de vocación, pues falta algo substancial a la misma. Lo único que se hace es descubrir no la vocación temporal, sino la ausencia de auténtica vocación.

Los formadores, ayudados de médicos expertos, han de encontrar tales anomalías, a fin de eliminar a su debido tiempo a quienes padecen dichos trastornos.

8 E. Cerdá. Una Psicología Hoy, 239.

9 Tomado de la revista Palabra núm. 44 (abril 1969) 14. 
La tarea no es fácil, al menos en algunas ocasiones. Por eso se puede cometer el error de que alguien se comprometa sin estar verdaderamente llamado. Al descubrir el error, habrá que enderezar las cosas.

En la tercera de las causas acude el P. Turrado a la llamada "psicología del' grupo" con sus múltiples interacciones. Dentro de esta perspectiva, un tanto general, fija su mirada en la llamada "política de los capítulos, que tanto daño ha hecho y sigue haciendo a las corporaciones religiosas". Finalmente hace alusión "a la democratización establecida for el Vaticano II y a la que se oponen ciertos grupos, tratando de seguir refugiándose en un pretendido endiosamiento de. las jerarquias de sur agrado".

Convengo en que pueden presentarse todos esos inconvenientes e inclusive otros muchos más. Mas ello no enerva, en absoluto, la perennidad de la vocación. Cuando se presenten esas cosas, un tanto extremas, será hora, no de retirarse, sino de plantear el problema y de estudiar la verdadera fisonomía de la vida religiosa, que hay que mantener siempre al margen de las posibles y reales desviaciones humanas. Para lo cual contamos con cosas muy positivas como son las orientaciones de la Iglesia. En ellas se encontrarán los elementos necesarios desde donde y a través de los cuales habrá que hacer el verdadero retrato de la vida religiosa. Cuando este examen nos lleve a la conclusión de que tal comunidad o instituto ha desvirtuado su auténtico sentido, será lógico pensar que en ellos concretamente resulta imposible la realización del ideal religioso. Y no quedará otro camino que la salida. Todo esto nada nos dice en favor de una posible vocación temporal. Se refiere tan sólo a que en tales circunstancias la vocación es irrealizable.

Después de estas puntualizaciones genéricas, cabe referirse a cada uno de los aspectos recogidos. Respecto a la psicología de grupo pueden aplicarse los principios expuestos acerca de la evolución psicofisiológica. Su influencia es real. pero no quiere deair que sea definitiva e insoslayablle. Si se diera en tales condiciones el religioso, seqún lo dicho anteriormente, puede y debe abandonar la vida religiosa. $\mathrm{O}$ mejor, debe buscar, fiel a la vocación que siente, otra comunidad en donde se realice como religioso. Lo grave de todo esto es encontrar una fórmula equilibrada. No siembre hay que hablar de situaciones extremas. En con. diciones normales el individuo cuenta, debe contar al menos, como consecuencia de su formación, con elementos de juicio para lograr sobreponerse a la psicología de grupo.

La politica de los capótulos es una mancha negra que afea á las comunidádes religiosas. Como tal, rebrobabilísima. Puede revestir caracteres verdaderamente dramátices y conducir al individuo a una total desilusión. En cuyo caso deben buscarse soluciones semeiantes a las que se apuntan en el párrafo anterior. Lo importante es saber distinguir situación y situación. Por eso la forma en que. 
el P. Turrado aborda este aspecto concreto no me parece acertada. A parte de que nada de esto desfigura la verdadera fisonomía de la vocación, y por tanto su perennidad, creo un tanto imprudente lanzar como doctrina de calle lo que debe permanecer en secreto y tratarse como tal. El conocimiento de la psicología humana nos lleva a esta conclusión. Lo contrario es abrir una puerta tan enormemente grande a la ilusión y a la fantasía que fácilmente puede servir de salida a la insinceridad y al egoismo. El religioso verá por todos los rincones el fantasma de persecución capitulera y como, consecuencia, encontrará pretextos constantes de abandonar el camino comprendido. Por eso creo que la solución no es ésa. No se puede dar como fenómeno general lo que es limitado ni predisponer al individuo para ver presiones donde tal vez no las hay. Demos otros principios en virtud de los cuales el religioso, como secuela de su consagración a Dios, sea capaz de superar esas situaciones extrañas. Sólo así se pueden hacer hombres, capaces de sellar con su heroismo la palabra dada.

El último aparte de esta tercera razón lo dedica el P. Turrado a la democratización, hecho que atribuye a la orientación y doctrina del Vaticano II. Sobre este punto habría que hablar largo y tendido. Por lo que hace a este respecto creo que basta lo siguiente: democratización es una palabra bonita, que puede servir para muchas cosas, inclusive para decignar una auténtica tiranía. De ella se usa y se abusa. Para muchos, democratización es sinónimo de desorden, o si se quiere, de hacer lo que a cada cual le viene en gana. El superior no pinta nada en la comunidad. ¡Pobre de él si se le ocurre llamar la atención! Claro, así todo es maravilloso. Mientras a uno no se le ponga freno... Esta forma de ver la democratización es esencialmente opuesta a la vida religiosa y a la doctrina del Vaticano II. Y lo es, porque destruye fundamentalmente el concepto y la práctica de lla obediencia, característica y razón de ser de la misma vida religiosa. "Repetidas veces han hablado en nuestros días los Sumos Pontífices de la abnegación icle la voluntad y la obediencia religiosa, ilustrándonos sobre el carácter sobrenatural de las mismas, sobre la diligencia y perfección con que los religiosos deben ejercitarlas y sobre ciertas ideas peligrosas en esta materia, como son principalmente un falso concepto de la personalidad y un cierto ambiente democrático que se van infiltrando sagazmente en los espíritus y que anulan totalmente la obedien. cia tal como la enseñó y practicó Nuestro Señor Jesucristo" 10.

En el punto extremo de esta falsa democratización está el endiosamiento de las jerarquías, al que se refiere el $P$. Turrado. Poctura a todas luces reprobable desde cualquier punto de vista que se la considere. El superior no debe consideranse como un pequeño o grande señor feudal. Su oficio es oficio de servicio. El súbdito tampoco debe endiosar al superior creyendo que nunca se equivoca

10 Sagrada Congregación de Religiosos. Instrucción, Roma 1961, p. 37.

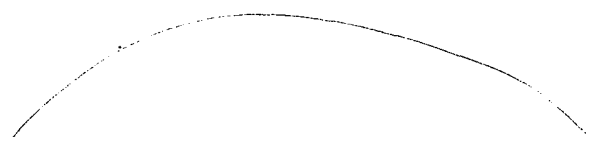


o que es impecable. Esto pudiera traducirse en un servilismo enemigo del éspíritu evangélico. Para evitar posturas extremas está el diálogo auténtico, en virud del cual los extremos, sin confundirse, se acercan lo más plosible. Nace así el clima de la confianza, absolutamente necesario entre suferiores y súbditos.

La verdadera visión de la convivencia religiosa nos coloca en el punto medio desde donde se puede ver la auténtica fisonomía del problema. Esta visión nace de la fe. $\mathrm{Y}$ a ella se refiere Pío XII con estas palabras: "En una época como la nuestra en que el principio de autoridad sufre grandes sacudidas, es absolutamente necesario que el sacerdote (religioso), firmemente apoyado en los principios de la $f e$, consideré y acepte la autoridad, no sólo como baluarte del orden social y religioso, sino también como fundamento de su misma santificación personal" ${ }^{11}$. Esta fe necesita cultivarse como soporte de nuestra vida religiosa. Con seguridad caerán ídolos que insensiblemente van levantándose en el fondo de nuestro corazón.

Finalmente alude ell P. Turradio all angelismo. Ve en él grandísimos peligros y ciertamente existen, cuando no se enfocan las cosas como se debe hacerlo. El centro de la cuestión está aquí. El religioso, como fruto de una adecuada formación, debe estar capacitado para valorarse y también valorar las cosas. $Y$ siempre volvemos a lo mismo. $Y$, en este sentido, creo que no hay por qué mirar las cosas desde el ángulo de vista peyorativo Sabemos que el religioso nunca deberá renunciar a los derechos fundamentales de la persona humana. Pero, en aras de una inmolación aceptada y hecha nor él libremente, habrá que exigirle aquello que, dentro de un onden normal, pide la fidelidad a su vocaciớn. De la toalabra angelismo hay que decir lo oue de tantas palabras. Van y vienen y nadie se para a reflexionar qué encierran. Esto nos lleva a calificar de angelismo posturas decididas que se sobreponen a los caprichos de nuestra naturaleza humana. Se me ocurre pensar que con la palabra angelismo sucede lo mismo o parecido aue con las palabras conciencia escrupulosa y conciencia delictda. A veces se califica de escrúpulo lo oue en realidad es fidelidiad a un querẹr delicado de Dios. Del mir. mo modo tachamos de angelismo la fostura de una persoma que trata por todos los medios de ser fiel a su vocación. En ecte caso habrá oue calificar de bendito angelismo dicha conducta. Estamos, pues, ante un término delicado oue se muede convertir, sino hay cautela, en un arma peligrosa. Lo que nunca será lícito es aban. donar el campo de batalla a las primeras de cambio, bajo el pretexto de oue un angelismo dulzón ha configurado nuestra vida.

Concluye el P. Turrado con oue "los designios de Dios" sobre una persona pueden manifestarse de muy diversos modos, puesto aue El es al mismo tiemro autor de la naturaleza y de la gracia" ${ }^{12}$. Esto es absolutamente cierto. Pero esta-

11 Pío XII, Menti Nostrae, p. 21, par. 16.

12 Art, cit. 526. 
mos siempre en una cuestión de principio. De una simple posibilidad no se puede deducir sin más ni más el hecho. Lo difícil es determinar cuándo es así. Lo que no me parece lógico es abrir una puerta por la que se pueda colar el pretexto y el engaño. Habrá que estudiar el caso con detención y obrar en consecuencia. Estaremos ante una excepción. Nunca, ante la regla.

Como conclusión a esta primera parte crítica, quiero recoger algunos pensa. mientos de una carta muy sensata, que dirige Guy Durand, casado y profesor de religión en Canadá, a los religiosos y sacerdotes. "Me espanta considerar la despreocupación con que ciertos sacerdotes y religiosos consideran su celibato $y$, de una manera más general, su género de vida. Me confiaba un amigo sacerdote, sonriendo maliciosamente: cuando esto no marche, me voy. Se niega cada vez más sintomáticamente el valor de los compromisos perpetuos. Doy como prueba de ello el resumen de la conferencia de un religirso (a quién, por otra parte, admiro) en un reciente congreso de religiosos. Después de haber indicado la necesidad de cambiar las estructuras sociológicas del pasado, añade:

$Y$ lo mismo hay que decir de lo que se refiere a todo lo que es inamovible, los votos perpetuos, los vínculos canónicos definitvos, etc. Tolo esto está ya concretamente sujeto a examen en la intimidad de la mayoría. (Devoir, 22 agosto de 1968).

Yo sé muy bien que se dan casos en que la opción, una vez tomada, ha de ser reconsiderada, aue caben nuevas orientaciones de una vida ordenada, en nom. bre mismo de la fidelidad que uno se debe a sí propio; pero no podré admitir que esto se haga a la ligera: esto sería un error de la humanidad; diría que un pecado contra el hombre.

Cuando un sacerdote, arrastrado por una corriente nada favorable al celibato y a su modo de vivir, no concede ya un valor práctico a su opción de vida, sino ora (no se para a saborear delante de Dios el sentido de su vida); si se expone a cualauier peligro. sin imrortarle el cómo y el cuándo; si busca el igualarse lo más posible a los laịcos, etc., Iṭor fuerza, tarde o temorano se irá, será reducido al estado laical...

Ya he dicho que, con frencencia, los religiosos no creen en los compromisos de por vida. Si fueran lógiros habrían de rechazar también el compromiso defi. nitivo del matrimonio ( $y$ aun del amor). Habrá que rechazar el significado mismo del bautismo, oue compromete para siembre. Poner en tela de juicio, por principio, la legitimidad de un comrromiso humano definitivo es suscitar una verdadera revolución cultural. Hav auuí un problema muy intrincado, digno de ser abordado. Pero conviene no ilusionarse con soluciones parciales e inadecuadas...

Volver a considerar no es dejar de hacer. Una cosa es la dolorosa constatación de un fracaso definitivo, no obstante una voluntad ardiente al servicio do un ideal fiel y estable, y otra, la destreocupación, si no la ausencia de ese ideal 
de amor. Quien jamás cultiva su amor acabará por bucear en otra parte y mancharse. ¿Qué sueño pensar que la infidelidad al celibato es como la prenda de la fidelidad a su amor! El amor, como el celibato, es un valor. Y un valor no se conserva, si no sc le protege, se le ama, se le cultiva. Un valor no es nunca una seguridad $\sin 0$ un compromiso...

Me parece que un compromiso humano profundo y global, como el que exige el amor humano o el celibato consagrado, ha de ser irrevocable en su as. pecto inicial : absoluto, definitivo. $\mathrm{Y}$ yo me pregunto si es que no se exige esta itrevocabilijlad de toda determinación que haya de ser integralmente humana.

La fidelidad a su vocación, ¿no es el nombre antiguo de un valor bien reciente: la fidelidad a sí mismo y a su opción de vida? Lejos de tratarse de algo jurídico como a veces se cree, la fidelidad es algo vital y valorizante.

Me pregunto también si, sacerdotes y religiosos, no están siendo juguete de un nuevo conformismo, por dejarse impresionar demasiado por las corrientes de pensamiento a la moda. Con la apariencia de una actitud muy personal, in que hacen es seguir la moda del día. ¿No será fruto de una secreta envidia el comportamiento de muchos sacerdotes y religiosos? Se envidia a los laicos casadols o, tal vez, el foder conjugar su puesto en el cielo con los placeres conyugales y familiares, o, también, se envidia a las personas que parecen maduras permitiéndose todas las libertades sexuales. Quien sabe si no se dará en el caso de la infidelidard al sacerdocio un ir refinadamente tras ide la gloria. Antes era mal visto abandonar la sotana; hoy esto atrae como un halo de admiración y glonia: precisamente lo que en otros tiemp̣os procuiraba la vidia sacerdotal y religiosa. Hoy el heroísmo está en perseverar. $\mathrm{Y}$ acaso también el profetismo.

Resumiendo, pienso que existe el valor de la fidielidad a sí mismo y a su elección de vida. Creo que el progreso en la humanización (de cada hombre y de las estructuras del mundo) es cuestión de esfuerzo y estimo que ningún valor (revolución social, amor humano o celibato por Dios) puede conservarse sino se le saborea, se le protege, se le cultiva.

El mundo actual está lanzando un desafío a los servidores del espíritu. Este desafío es más temible para aquellos (sacerdotes, religiosos o laxicos) que están al servicio del Espíritu. Aquí está el fondo de este problema: ¿Creemos bastante en la Buena Nueva del Espíritu para llenar de ella nuestras propias existencias?" 13.

\section{RAZONES EN DEFENSA DE UNA VOCACION DEFINITIVA}

Por si no ha quedado claro, y para que nadie atribuya a estos raciocinios un valor que no tienen, tengo que referirme a su alcance. No se trata de casos

13 Carta tomada de la revista Vida Religilosa 26 (1969). 
particulares, en los que razones de peso impongan un cambio de escena. Esto puede existir y existe de hecho. La razón última del fenómeno se encuentra en la misma dinámica de la vida religiosa. Nadie puede tener una certeza absoluta, a no ser por revelación, de que Dios le llama al estado religioso y, además, si se quieren llevar las cosas a sus últimas consecuencias, en determinada orden o congregación. Se trata tan sólo de una certeza moral. Y esta certeza es la que más variantes presenta. Es decir, pueden ser frecuentes los casos en que un estudio más detenido conduzca a la falta de vocación.

De aquí no se deduce, sin más ni más, que quien abandona la vida religiosa carezca de vocación. Para llegar a esto, habrá que estudiar cada caso en particular. Muchos abandonan la vida religiosa, no por falta de vocación, sino porque la infidelidad ha hecho imposible su realización. "Estimo que ningún valor (revolución social, amor humano o celibato por Dios) puede conservarse sino se le aprecia, se le saborea, se le protege, se le cultiva" ${ }^{14}$. Por tanto nada definitivo se puede decir aceroa de la temporalidad de la vocación en función de la Estadística. No siempre está la vendadera causa del abandono de la vida religiosa allí donde la sitúa el interesado. Y la Estadística usa los datos que el intenesado apporta.

Con estos antecedentes se puiede abordar ya el tema de este epígrafe. Sé trata de una exposición incompleta, plor lo que a materia se refiere. Es demasiada para ppoderla recoger en los párrafos de este estudio. No así, por lo que mira al tema concreto. Pienso que las razones, que se van a aducir, son lo suficientemente claras, como para crear en cada uno de nosotros la convicción de que la vocación religiosa, si de hecho existe, es de suyo para toda la vida.

Ensamblo en una visión de conjunto la doble esfera, que pudiera distinguirse en el hombre, como conseculencia de su elevación al orden sobrenatural. Con in cual no hago más que considerar al hombre en su situación histórica actual. Lo sobrenatural, en esta perspectiva, entra en el marco histórico del hombre, de forma aue toda visión del hombre, aue ourescinda de esta nueva situación, será una visión incompleta.

En consecuencia, la vocación no sólo se mirará como fenómeno sobrenatural, como iniciativa divina, sino también como fenómeno humaro en la forma y amplitud oue se ha explicado. Habrá, tror tanto, interrelación entre uno y otro aspecto...

Al referirse a la vida religiosa, el Vaticano II se expresa en estos términos: "Por los votos, o por otros sagrados vínculos análogos a ellos a su manera, se obliga el fiel cristiano a la práctica de los tres Consejos Evangélicos antes citados, entregándose totalmente al servicio de Dios sumamente amado, en una entrega

14 Artículo antes citado y tomado de la revista Vida Religiosa. 
que crea en él una especial relación con el servicio y la gloria de Dios. Ya por el bautismo había muerto al piecado y se había consagrado a Dios. Ahora, para conseguir un fruto más abundante de la gracia bautismal, trata de liberarse, por Ia tprotesión de los Consejos Evangélicos en la Iglesia, de los impedimentos que ppodrían apartarle del fervor de la caridad y de la perfección del culto divino, y se consagra más íntimamente al servicio divino. Esta consagración será tanto más perfecta cuanto por vínculos más firmes y más estables se represente mejor a Criisto, unido con vínculo indisoluble a su Esposa, la Iglesia" ${ }^{15}$. En la misma línea se mueve el documento dedicado a la vida religiosa. "Piensen los miembros de cualquier Instituto que por la profesión de los Consejos Evangélicos respondieron a la vocación divina, de forma que vivan prara Dios, no sólo muertos al pecado (Cfr. Rom. 6, 11), sino también renunciando al mundo. Entregaron toda su vida a su servicio, lo cual constituye una cierta consagración peculiar, que se funda íntimamente en la consagración del bautismo y la expresa en su totalidad.

Los religiosos, pues, frieles a su profesión, dejándolo todo por Cristo (ofr. Mc. 10, 28), síganle a $\mathrm{El}$ (cfr. Mt. 19, 21) como la única cosa necesaria (Lc. 10, 42), oyendo sus palabras (cfr. Lc. 10, 39), solícitos de los intereses de Cristo (ofr. I Cor. 7, 32).

Por lo cual los miembros de cualquier Instituto, buscando ante todo y única. mente a Dios, deben unir la contemplación para adherirse a $\mathrm{El}$ con la mente y el corazón, con el amor apostólico que les impulse a asociarse a la obra de la redención y a extender el reino de Dios" 16.

Late en lo más íntimo de estos párrafos un reconocimiento claro y una proclamación solemne de la perennidad de la vocación. Para comprenderlo, fijémonos en la virtualidad de las palabras. Se nos dice que la práctica de los Consejos Evangélicos crea una especial relación con el servicio y la gloria de Dios... Que lleva consigo una consagración más íntima al divino servicio...

Que cuantos más firmes y estables sean sus vínculos mejor representan a Cristo unido con vínoulo indisoluble a su Esposa, la Iglesia. Es este un lenguaje de resonancias eminentemente vitales. Todo se mueve en un marco de entrega generosa. Y, pror ello, se recuerda la entrega más desinteresada, rubricada con vínculo indisoluble, que ha existido, que es la de Cristo por su Iglesia. La profesión expresa esta entrega. Ya por este solo simbolismo habría que piensar en la perennidad die da vocación. Como Cristo sella su amor a la Iglesia con vínculo indisoluble, así el religiosos debe hacerlo por la profesión. Mas con ser esto de una fuerza enorme, tal vez no esté aquí el fundamento último de lo penennidad de la vocación. Para mí se encuentra en el contenido de la palabra entrega. La

15 L. G. Par. 44

16 P. C. Par. 5. 
profesión, si es verdaderamente tal, pror tanto me refiero a la definitiva al menos intencionalmente, debe nacer como consecuencia de una entrega de amor. La entrega, que merece el nombre de tal, lleva consigo una serie de cosas, que no es lícito olvidar. En primer lugar, ha de hacerse en conformidad con una jerarquía de valores. En segundo, consciente y libnemente. En teroero, generosa y desinteresadamente. En síntesis: en amor auténtico. Ahora bien, ¿cómo puede nevocarse una entrega, a la que uno es llamado en libertad, cuando se trata de Dios, supnema valor de la vida? Y la pregunta no se refiere al hecho. Consta que se da. Mira simplemente a lo que debe ser, según las exigencias de la entrega. La entrega auténtica excluye, psicológicmente hablando, todo abandono del camino emprendido. Decir lo contrario es desvirtuar en absoluto su valor transoendental. "Los religiosos, prues, fieles a su profesión dejándolo todo por Cristo (cfr. Mc. 10, 28), síganle a El (cfr. Mr. 19, 21) como la única cosa necesaria (cfr. Lc. 10, 42), oyendo sus palabras (cfr. Lc. 10, 39), solícitos de los inteneses de Cristo (cfr. I Cor. 7, 32"17. "Con las palabras vínculos más firmes y más estables el Concilio se refiere a los votos o vínculos perpetuos. Afirma que la perpetuidad del compromiso hace más perfecta la consagración. Esta afirmación no es superflua en una época en que algunos se inclinan a ver como ideal un régimen de vida consagrada en el que el compromiso siguiera siendo temporal y debiera renovarse cada año. Semejante régimen puede halagar la inclinación a la libertad. Por otra parte, puede también ser conveniente para los cristianos que limitan delibenadamente el tiempo de su entrega al servicio de la Iglesia. En ese sentido cabe hablar de vocación temporal, de un llamamiento a entregar algunos años de la vida al Señor, con entera disponibilidad, pero con la intención de pasar después al camino nonmal del matrimonio. Sin embargo, la consagración no puede ser perfecta, si no lleva consigo una pertenencia definitiva al Señor. La vocación a la vida religiosa es en sí perpetaca, y, cuando Dios llama a la cumbre del amor en la castidad virginal, exige una entrega sin limitación temporal. Una entrega provisional no puede ser una entrega plena. Por ello el religioso, al hacer su profesión temporal, lo hace oon la resolución de asumir más adelante un compromiso iperpetuo.

Si reflexionamos en lo que significa la consagración, obra de Dios que toma al ser humano para vincularlo a sí y para transformarlo de esa manera en sagrado, tendremos que reconocer que toda verdadera consagración exige par sí misma una duración sin fin. No cabría darse a Dios y dejarse tomar por El, para volver luego a tomarse a sí mismo. La toma de posesión del ser humano por el Ser absoluto tiende a una posesión sin límites y asegura a esa pertenencia un pro.

17 P. C. Par. 5. 
der inconmobible que el hombre, con los límites de su variabilidad, jamás podría dar por sí mismo.

El Concilio pone en claro todavía desde otro punto de vista el carácter perpetuo de la consagración: Por ella se representa a Cristo unido con vínculo indisoluble a su Esposa, la Iglesia (L. G., 44). La indisolubilidad del vínculo que une a Cristo con la Igleșia es el fundamento de la indisolubilidad del víncula ide la profesión petpetua" 18. "Si se tiene una percepción algo clara de los elementos que constituyen una verdadera vocación, no es difícil descubrir por qué caminos tendrá que llegar su pérdida y destrucción.

Se habla de perder la vocación y esto, hablando con rigor, puede no ser exacto. La vocación es originariamente un acto de Dios, definitivo y sin arrepentimiento pasible. La vocación es el modo personal y concreto de realizar sobnenaturalmente nuestra vida personal del modo más perfecto y provechoso posible, conforme a los designios divinos. Dios nos llama a todos a la mayor perfección posible y a la vida que sea más fructuosa en la Iglesia atendidos todos los condicionamientos personales y sociales de nuestra vida que El tiene perfectamente en ouenta. En este sentido la vocación es innevocable y no se puede perder.

Lo que sí cabe es que uno corresponda o no a la vocación a la que se siente llamado. En este caso, es más exacto hablar de infidelidad a la vocación, al Dios que nos llama. Hay en el fondo una rebeldía, una sujeción a las cosas de este mundo, a la propia independencia más o menos grave cuanto más clara sea la vocación de Dios y más definitivamente nos alejamos de ella" 19. "Por medio de la profesión religiosa nos entregamos como don perpetuo e irrevocable para ser quemados enteramente como holocausto en el fuego de caridad del Espíritu Santo" 20.

Las citas son lo suficientemente elocuentes y ellas bastarían para probar, a la luz de la doctrina conciliar, que la vocación es de suyo para siempre. Podría pues, poner aquí piunto final. Con todo creo que se puede enriquecer aun más este contenido. Pur lo que me permito seguir estudiando el concepto vocación.

Vocación, un término suficientemente conocido, significa llamada. Por ella la vida del hombre se circunscribe y encauza. $Y$, al mismo tiempo, se potencializa. "El yo, el yo tprofofundo, radical, sólo se realiza, se logra en plenitud por uno, por un determinado y concreto camino, de esos caminos que se le presentan ante su mirada multiforme. Es su destino. Su proyecto vital. Su sitio. Es su vocación. Sólo pror ahí llegará a ser auténtico, a ser él mismo, a conseguir esa personalidad, a que su persona con sus circunstancias individuales está llamada, no determinada.

J. GaLOT, Nueva perspectiva de la vida consagrada, 103-105.

F. Sebastíńn Aguilar, Vida Evangélica, 74.

Paul Hinnebusch, La vida religiosa, Liturgia viva, 143. 
La vocación es, una invitación. Pero una invitación que se hace al hombre para que él rinda al máximo de sus posibilidades nelativas y limitadas. Para que sea auténtico. Para que no fracase como un ser en parte o por completo inútil. Para que no se falsifique.

La vocación implica una misión. Es para algo. Ortega minimiza, sicologiza la noción de misión. Para él misión es la conciencia que cada hombre tiene de su más autêntico ser que está llamado a realizar. La idea de misión, es, pues, un ingrediente constitutivo de la condición humana. Y sin hombre no hay misión, podemos añadir: sin misión no hay hombre.

Todo hombre es, pues, un llamado, un destinado para algo. La misión es la que hace la vocación. Lo funcional es aquí previo en la visión, aunque venga después en la ejecución, en la realidad existente. Quiere decir que da vocación humana es impensable sin el ser que da proyecta y la hace posible" ${ }^{21}$.

La fuerza de estos pensamientos nos conduce a una conclusión seria, muy seria en la tarea del vivir, que, en el fondo, es la más radical y primera de las vacaciones: La llamada pide una respuesta. Respuesta que, ipor necesidad, no puede ser indiferenciada, sino concreta; respuesta que ha de moverse en la línea y en el contenido de la llamada; respuesta que el hombre ha de dar generosa y libremente. De esta respuesta, tal como se acaba de describir, depende, en mayor o menor escala, la autenticidad de nuestra vida. "La llamada exige una respuesta. Respuesta libre, decidida, generosa, de la cual depende mi futuro. La fecundidad o la inutilidad de mi vida está, por consiguiente, en mis manos. Responder a mi vocación, es decir, vivir auténticamente, es mi grande, mi vital compromiso" 22 .

Es cierto, y se acaba de reconocer, que el hombre no está necesariamente empujado a dar la respuesta. Ha de hacetlo generosa y libremente. Mas la fidelidad o infidelidad a la vocación no queda reducida a la categoría de un hecho cualquiera en la vida del hombre. Ellas comportan la autenticidad o inautenticidad de la misma. Ya sé que todo esto admite gradbs. Que hay que distinguir y que no toda infidelidad a la vocación lleva consigo el mismo firacaso. La gravedad del fracaso está en razón directa de la forma en que la vocación afecta a la vida. "Así el matrimonio, la consagración en la vidas religiosa, el sacerdocio, son realidades que compontan un estado de vida.

De vida... No se trata de aspectos particulares ni de momentos parciales die la misma, por importantes que ellos fueran: profesiones, negocios, obras anriesgadas..., sino de ailgo que afecta a toda ella $y$, por consiguiente, a todo ese ser que vive.

Esa llamada divina a algo tan penetrante en la vida del hombre marca el

21 Baldomero Jimenez DuQue, Vocación sacerdotal, 20.

22 ID., O. c., 30. 
destino especial de esa vida, la cual tiene que enfocarse y vivirse en función del mismo.

$Y$, por ende, tiene que producir en ese hombre una resonancia vital, natural y sobrenaturalmente hablando, que viene a ser parte constitutiva de su forma integral de ser. Tiene allí que darse una huella, un eoo de la llamada para que ese hombre pueda responder libremente a la misma. Esa respuesta será realizar su destino vital, 0 , si se quiere, es su diestino vital en movimiento.

Descubrir esa vocación pianticular y responder a ella es por lo tanto importantísimo. Es descubrir aquello para lo que estamos destinados, y por eso psicológica, vitalmente hechos. Es encontrar nuestro especial camino, nuestro sitio concreto, aquello por donde la vida, mejor, nuestro existir, se logrará en la plenitud posible, y por eso será más rentable y más fecundo. $Y$ de rechazo, inevitablemente y en un hondo sentido, más feliz. Una vocación no es otra casa que un adquirir conciencia del centro de perspectiva que permitirá al yo crear en sí mismo y en su vida la mayor unidad posible. Es, por consiguiente, encontrarme con mi núcleo, con mi radicalidad personal, más íntima y más profunda. Es ser yo mismo. Ser fiel a mí mismo. Ser auténtico" 23.

Realmente, la vacación religiosa, vista a la luz de estos principios, está exigiendo la perennidad. Para ser más exactos, habrá que añadir que no se ooncibe sin ella. Afirmar lo contrario es destruir su riqueza y su valor. Es, además, crear una situación psicológica insostenible, que, por fuerza, conduce a la angustia. Esto pudiera parecer una paradoja o, si se quiere, un contrasentido. No lo es, aunque, a primera vista, parezca más tranquilizante hablar de una vocación temporal, a la larga los resultados son más inquietantes.

Reconozoo que la vida del hombre tiene que moverse en una cierta inseguridad, inclusive por lo que se refiere aún a la vocación religiosa. Ningún hombre sabe con certeza absoluta, si el camino elegido responde a una elección real. Para esto habría que contar con una revelación por parte de Dios. Ello ha existido, como nos lo recuerdan los Libros Santos. Mas no es la ley ordinaria. El hombre ha de trabajar con los elementos que tiene a su alcance. "Tenemos que bucear en nosotros mismos para encontrar la huella de su llamada, impresa vitalmente en nosatros. Tenemos que vivir.

Por eso, más que preguntarnos: ¿Qué querrá Dios de mí?, deberíamos pre. guntarnos: ¿Qué puedo y quiero dar yo al Señor para tendir al máximo? Pues en ese pader y querer está implicado nuestro estado de vida, es decir, el llamamiento a lo que le iproduce y determina. Allí se manifiesta, allí se descubre, hecho carne en nosotros. Es la inspiración, la llamadia de Dios, que así, de manera ordinaria, se nos desvela" 23.

23 ID., O. c., 42. 
Ni esencial ni existencialmente se puede admitir la temporalidad de la vocación como fenómeno ordinario. Sólo se debe hablar de vocación temporal en casos particulares, pues Dios, principio y razón última de la misma, puede actuar al margen de la ley ordinaria.

P. Benito Domínguez, O. S. A. 